\title{
Prosthetic Myoelectric Control Strategies: A Clinical Perspective
}

\author{
Aidan D. Roche $\cdot$ Hubertus Rehbaum • \\ Dario Farina · Oskar C. Aszmann
}

Published online: 25 January 2014

(C) Springer Science + Business Media New York 2014

\begin{abstract}
Control algorithms for upper limb myoelectric prostheses have been in development since the mid-1940s. Despite advances in computing power and in the performance of these algorithms, clinically available prostheses are still based on the earliest control strategies. The aim of this review paper is to detail the development, advantages and disadvantages of prosthetic control systems and to highlight areas that are current barriers for the transition from laboratory to clinical practice. Current surgical strategies and future research directions to achieve multifunctional control will also be discussed. The findings from this review suggest that regression algorithms may offer an alternative feed-forward approach to direct and pattern
\end{abstract}

This article is part of the Topical Collection on Trauma-Related Prosthetic Surgery.

A. D. Roche $(\bowtie)$

Academic Foundation Program, Newcastle upon Tyne NHS

Trust, Freeman Hospital, Newcastle upon Tyne, UK

e-mail: aidan.roche@newcastle.ac.uk

\section{A. D. Roche · O. C. Aszmann}

Christian Doppler Laboratory for Restoration of Extremity Function, Division of Plastic \& Reconstructive Surgery, Department of Surgery, Medical University of Vienna, Vienna, Austria

e-mail: oskar.aszmann@meduniwien.ac.at

\section{H. Rehbaum · D. Farina}

Department of Neurorehabilitation Engineering, Bernstein Focus Neurotechnology Göttingen, University Medical Center Göttingen, Georg-August University, Göttingen, Germany

e-mail: hubertus.rehbaum@bccn.uni-goettingen.de

D. Farina

e-mail: dario.farina@bccn.uni-goettingen.de recognition control, while virtual rehabilitation environments and tactile feedback could improve the overall prosthetic control.

Keywords Prosthetic - Myoelectric · Pattern recognition · Regression control · Virtual rehabilitation environment

\section{Introduction}

Myoelectric control of prosthetic upper limbs is an established technology [1]. While cosmetic features, weight savings, battery life, and components have significantly improved over time, the fundamental control strategies in the clinical setting have not changed [2•] (Fig. 1). Amputees still control prostheses by using one muscle group to open the hand, and another to close the hand, with some advanced devices allowing movements at the wrist or specific grip patterns. The early strategies of on/off and proportional control have been shown over a number of decades to perform well, with consistent reliability [3, 4]. However, this is far from the capability of the natural human hand, which can frustrate prosthetic users, especially in an era of relentless technological innovations.

In contrast to early approaches that work on one to two degrees of freedom, pattern recognition and other machinelearning algorithms have the potential capability to map more movements over multiple degrees of freedom, by deciphering the useful features present within the electromyographic (EMG) signal [5]. This capability is promising, but has not yet been applied in widely available prosthetic hands, despite being in development since the mid-1970s. Deciphering EMG signals in real-time is not a cost-free exercise and requires significant processing power. 
Fig. 1 Examples of myoelectric hands commercially available. Although they differ in complexity and components, with some offering different grip patterns (adjustable by external means), all are based on the earliest control strategies to achieve grip. a Ottobock DMC Plus. b Touchbionics iLimb. c Ottobock

Michaelangelo hand. d RSL Steeper Bebionic. b-d The most advanced clinically available hand prostheses at time of publication, while (a) is typical of a terminal device that is widely used in clinical practice (a)

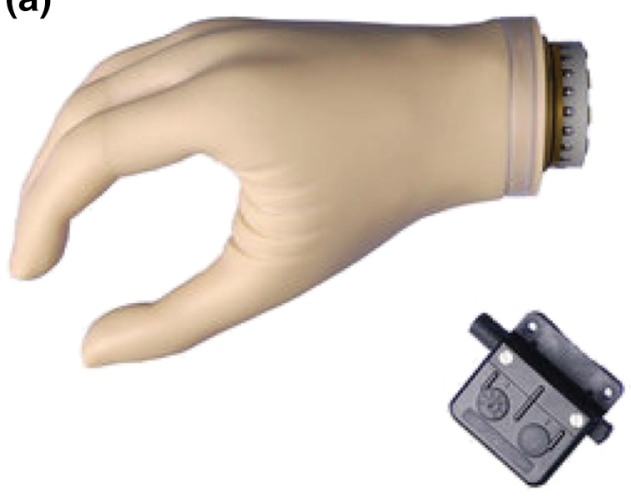

(c)

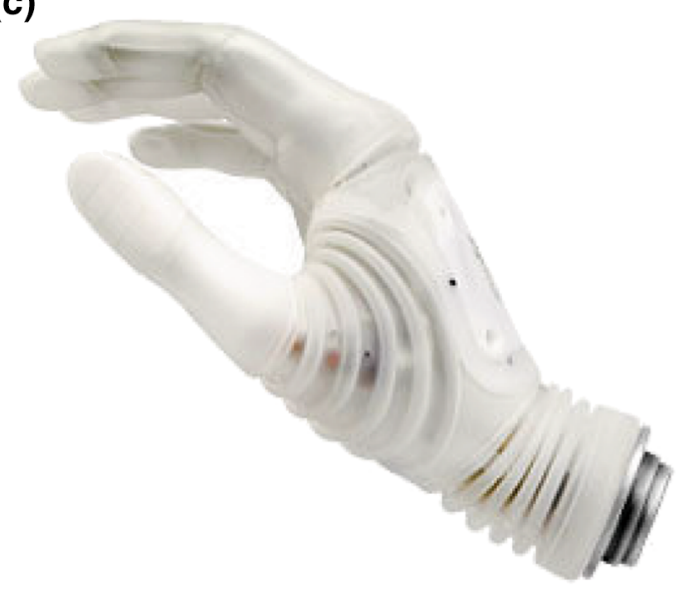

(b)

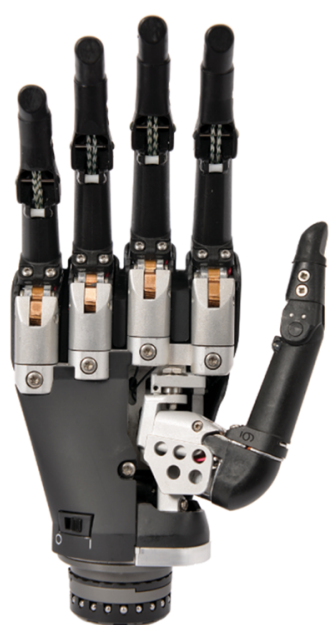

(d)

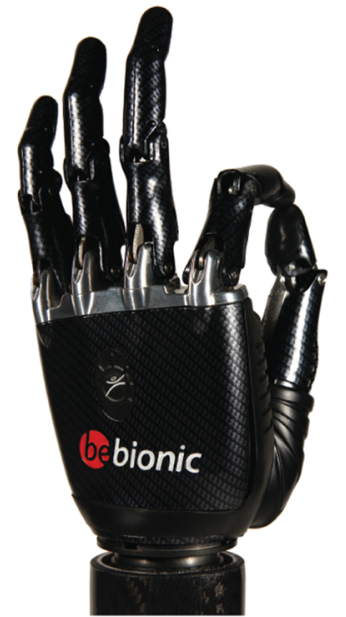

Moreover, the reliability of pattern recognition methods when used in daily living conditions is challenged by several factors of variability, such as changes in arm posture, electrode repositioning, and fatigue [6].

This review sets out to examine from a clinical perspective why simple proportional and threshold-based strategies are currently the only options for clinical devices, and what challenges still need to be addressed for surpassing the limitations that more advanced academic systems face before their more extensive use will be possible.

\section{Early Developments}

Historically, the first electronically-driven hand prostheses were pioneered by Reinhold Reiter at the end of World War Two [7], followed by subsequent groups [8-12]. Uncomplicated in nature, these early myoelectric hands used EMG signals from either one or two muscle groups to determine an 'on' or 'off' state to control the myoelectric limb.
In the case of one muscle group, engineers took advantage of the varying intensity of muscular contractions to determine suitable activation thresholds that would trigger a particular action or 'state' of the prosthesis. Variously known as on/off control, crisp control, finite state machine control, or onset analysis, these threshold-based methods allowed actions such as slight contraction to close the hand, strong contraction to open, and no muscle activity to halt the device [8] (Fig. 2a). The same technique could be applied to two opposing muscle groups, such as flexors and extensors, to control hand opening and closing [11]. Various thresholds can be used to determine which EMG activity is relevant and to discriminate from the background noise [13]. Although both fast and applicable to real-time applications [14], the number of movements generated is limited and the control is sequential in nature, unlike the smooth actions expected of the human hand.

An early alternative to the binary nature of on/off control was to vary the velocity and force of the prosthetic hand in a continuous and proportional manner to the recorded EMG signal from two opposing muscle groups to 
Fig. 2 A simple illustration of the early control strategies used when a one electrode is used to generate three states, and $\mathbf{b}$ two electrodes determine opposing actions
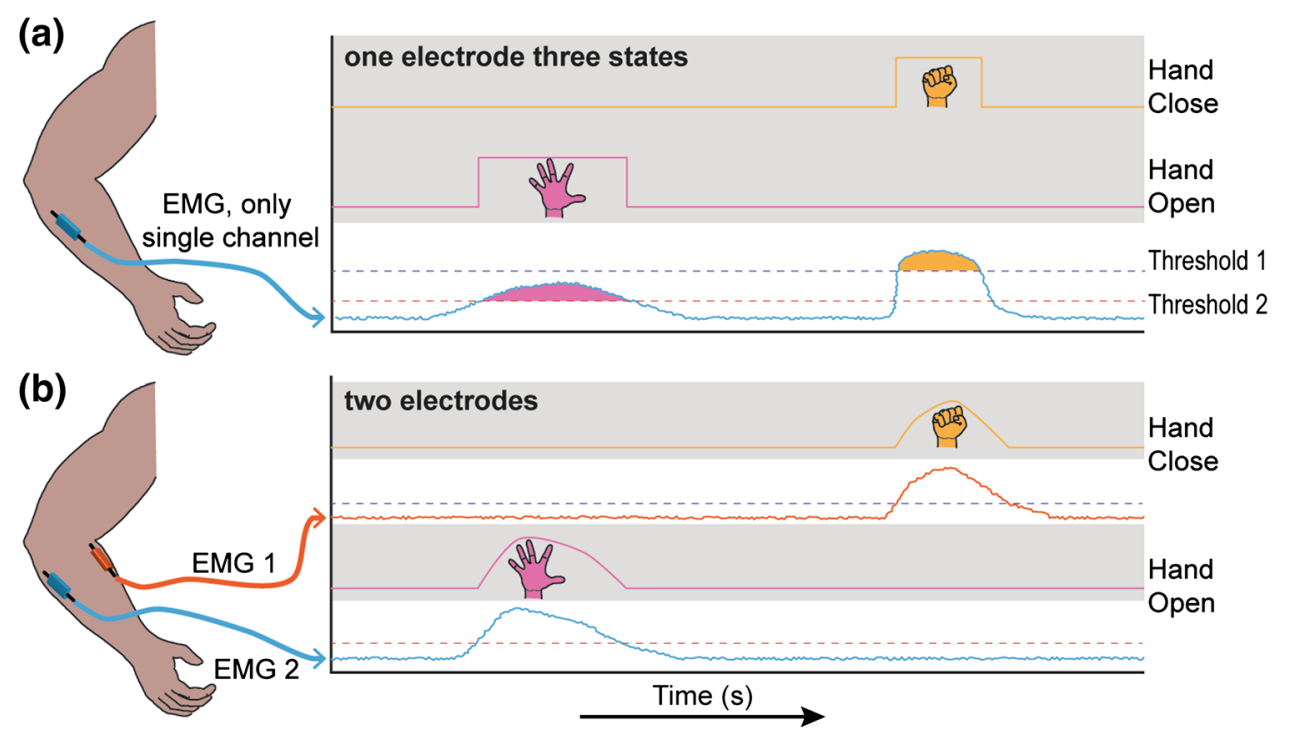

achieve hand open/close [15, 16] (Fig. 2b). This type of control has been previously defined as proportional control, where users control "at least one mechanical output quantity of the prosthesis (whether that be force, velocity, position, or any function thereof) within a finite, useful, and essentially continuous interval by varying his/her control input within a corresponding continuous interval", and is found in many clinically available devices [17•]. While this type of control is acceptable for large gross movements, such as hand open/close, it is insufficient for finer movements such as individual finger flexion.

Proportional control could, in principle, be refined further to accommodate fine movements by mapping individual EMG signals to individual functions of a prosthetic device in a process known as direct control [18]. However, this requires overcoming the interference of several muscles contracting together, which generate crosstalk of the resulting EMG signals, reducing the selectivity of the electrodes for individual EMG signals [19]. One method to overcome crosstalk is to implant recording electrodes directly into [20, 21] or onto [22] muscles, which have been shown to be a feasible approach in animal studies.

Whilst fast and robust, the number of movements generated by proportional and direct control systems is limited by the number of independently controllable EMG channels. As a result, current prosthetic upper limbs are mostly limited to such simple functions as generating power grip or elbow flexion/extension, far from the multifunctional control of the human arm. In light of this, newer pattern recognition control strategies have been developed experimentally to overcome the lack of multifunctional control [23], by providing many more degrees of freedom while using the same number of channels.

\section{Pattern Recognition Control}

Introduced to the prosthetic research community around 1970, and tested in research conditions, pattern recognition algorithms provided a means for multifunctional control by classifying different muscle activation patterns [23-25]. These algorithms fundamentally included a sequence of events where the raw EMG data was first windowed, and useful features extracted and classified, before being used for control (Fig. 3). However, these systems did not generate great interest until 1993, when Hudgins et al. [26] showed that a more refined interpretation of the content of the EMG signal could be achieved, setting the basis for a rising wave of pattern recognition control algorithms $[5,27]$.

The development of these algorithms included increasing the number of input channels [25], which improved the accuracy of classifying features [28] and the resulting multifunctional control. This has allowed increased movement patterns to be classified beyond just grip, to include wrist flexion and extension, forearm pronation and supination [29, 30], humeral rotation [31] and ulnar and radial deviation at the wrist [32], with the current trend moving towards identifying muscle patterns to control individual fingers [33-36]. However, it is important to note that pattern recognition is only capable of classifying these movements in sequence and not simultaneously (Fig. 4a).

While these advances in pattern recognition are encouraging, there are several factors that prevent transition from the laboratory to clinical application. Most laboratory testing involves either healthy volunteers or amputees in static conditions [37]. This is notable, as the training and testing datasets used for pattern recognition 


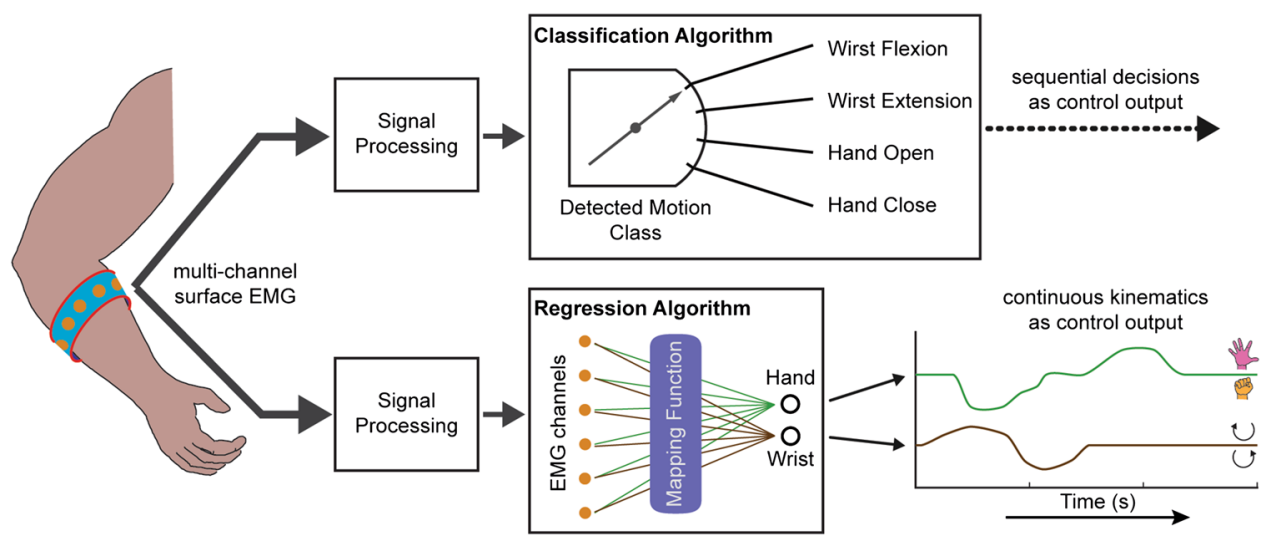

Fig. 3 Comparison of the structure for pattern recognition (upper) and regression control (lower). For pattern recognition, a classification algorithm identifies the currently active function, resulting in a sequence of decisions at constant update rate. For the regression algorithm, a mapping function translates the information extracted from the EMG signal into continuous kinematics that can be used as control signals for a prosthetic device
Fig. 4 a Pattern recognition is able to classify different movement patterns, but only in sequence, which limits multifunctional control. b Regression control is able to identify different movements at the same time, leading to more intuitive prosthetic control
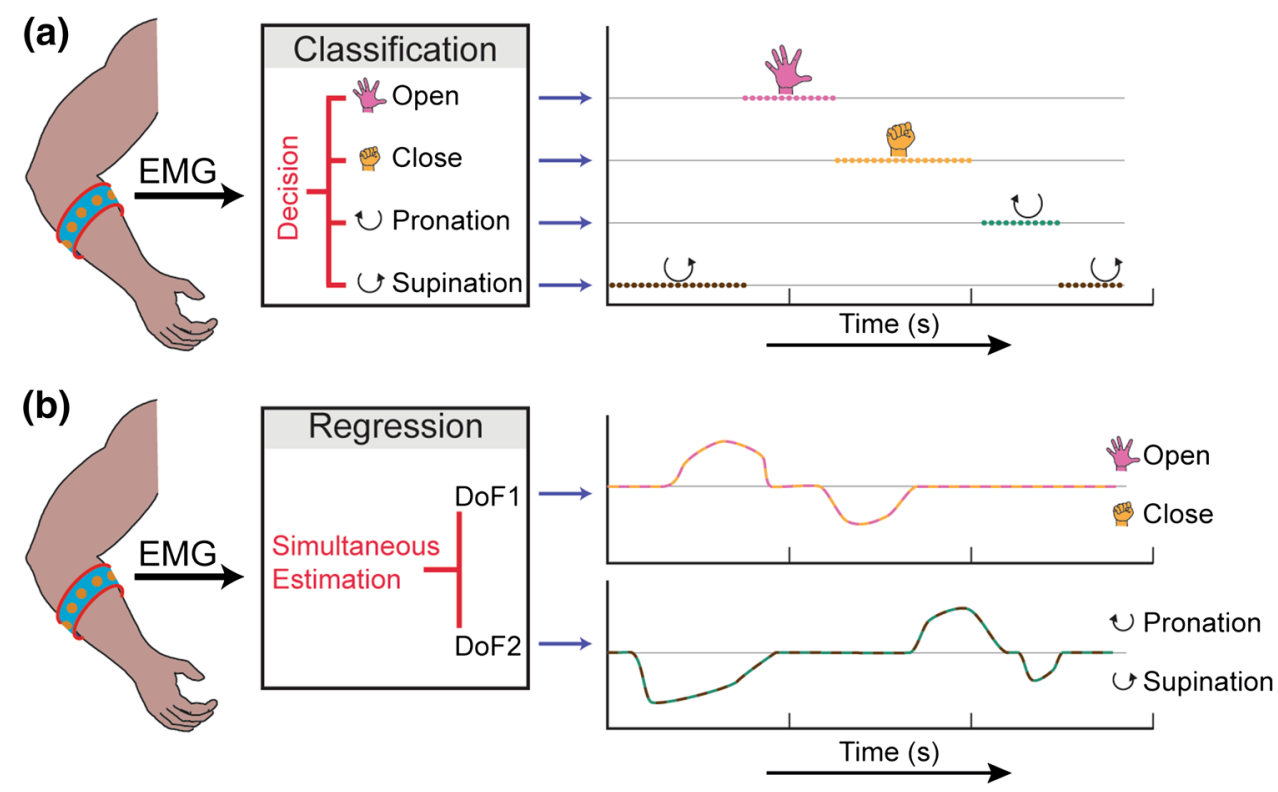

[38•] have been collected in these conditions, when muscle contractions would be ideal and exclude the interaction of the user with the control system in real-life situations. The muscle contraction patterns can change when the user has to act in stressful situations or react to wrong movements. In addition, during active movement, the effects of sweating and displacement of the electrodes, as well as changes of the muscle size and shape post-surgery, can influence the EMG signal characteristics. The effect of some of these factors can be mitigated, such as increasing the distance between surface electrodes [39] and alignment with respect to muscle fibres [40] to improve signal acquisition. However, the results from offline validation often cannot be easily translated into real-world situations [41].
An example of the difficulties in translating laboratory results to real-world applications is the way in which performance is reported in research studies, as classification accuracy. The association between classification accuracy and prosthesis usability is very weak. For example, in realtime testing of myoelectric pattern recognition control of a virtual arm by transradial amputees, the completion rate of predefined hand movements with the prosthesis was only $\sim 55 \%$ when the classification accuracy was $\sim 85 \%$, suggesting that these algorithms are insufficient to reliably control real-time hand grasp even for relatively high classification performance [6]. Moreover, pattern recognition methods inherently require sufficiently long intervals to extract useful classification features without delaying response time. Optimal controller delays have been 
suggested to be $100 \mathrm{~ms}$ for fast prehensors and $125 \mathrm{~ms}$ for slow prehensors, without degrading the prosthesis performance [42], while delays longer than $200 \mathrm{~ms}$ have been shown to negatively affect a user's performance [43]. Despite these considerations, laboratory studies on pattern recognition [44-47] usually report results for internals of $300 \mathrm{~ms}$. Although in simple cases of one degree of freedom control, it has been shown that high accuracies are still obtained with shorter intervals [48], the performance usually degrades substantially as the processing window decreases.

In real-world situations, losing prosthetic control, such as while holding a pan of boiling water, would not only be undesirable but unsafe. Thus, a robust system is preferable to one that is technologically complex yet unreliable. Supportive of this view, a review of the English language literature over a 25-year period observed that, while technology had improved, prosthetic limb rejection rates have not been decreasing, with $35 \%$ of paediatric and $23 \%$ of adult amputee populations discontinuing use of their prosthetic limb [49]. In a separate study, $13.4 \%$ of Norwegian major upper limb amputees discontinued use of their prosthesis mainly due to poor prosthetic comfort, function and control [50].

\section{Regression Control}

Improving how patients control prostheses, while overcoming the limitations of existing control strategies, is necessary to improve acceptance. Two major limitations of pattern recognition approaches are the lack of simultaneous multifunction control and of proportional control. In the case of a prosthetic hand with the four functions of hand open, hand close, wrist pronation and wrist supination, a classifier can only detect one function at a time. A simultaneous opening of the hand together with supination, for instance, to prepare the hand to grasp an object, is not possible [51]. In order to provide a solution for this problem, some research groups have proposed using additional classes for all combinations of functions [52] (for the above example, an additional class would be "hand open + wrist supination"). However, the combined classes increase the number of patterns that need to be trained, which is undesirable in clinical practice as it increases the time of the user necessary to train the system. Secondly, pattern recognition does not support proportional control of the prosthesis, crucial for optimising the speed of the response. Like a switch, a classifier can only decide an on/off basis, but, in most cases, the user also needs to be able to influence the speed or strength of the prosthetic device. This requires adding a proportional component to the control signal $[17 \bullet, 26,53]$, which can increase the overall complexity of the device and decrease the robustness of the control.

Newly developed regression algorithms overcome the need to increase the complexity of the device whilst providing simultaneous and proportional control. In contrast to methods only allowing classification of one motion at a time, regression algorithms are able to continuously estimate multiple control signals directly from the EMG signal (Fig. 4b). For the same prosthesis functions as above, this results in one control signal for the rotation angle of the wrist and a second estimate for the opening angle of the hand. Consequently, the regression approach provides greater flexibility for the user, leading towards a more intuitive prosthesis control paradigm. Examples for this control concept found in the literature are based on NonNegative Matrix Factorization [54, 55, 56•], Artificial Neural Networks [57-62], or Linear Regression [63], allowing two or more degrees of freedom to be activated simultaneously and proportionally. Notably, some of the limitations of pattern recognition systems have been addressed using regression approaches, such as electrode shift [64]. The regression method has so far provided promising performance, allowing direct and intuitive control for the user, and developments in the near future are likely to further strengthen the robustness of this approach.

\section{Surgical Methods to Improve Control}

An alternative to developing algorithms to decipher EMG signals is to record from individual muscle groups. Aside from implanting electrodes, another method to overcome EMG crosstalk is to surgically isolate nerves and amplify their signals through targeting muscles of interest.

In 1995, Kuiken et al. [65, 66] demonstrated in rats that injured muscles could be hyper-reinnervated with additional nerves to encourage increased strength and muscle mass, while also proposing that this technique could provide additional EMG control signals for some amputees. In subsequent studies, it was also noted that subcutaneous fat dampened EMG quality [67], and that reduction of this fat could increase EMG amplitude and independence [68]. In 2004, the group went on to show, in a bilateral shoulder disarticulation amputee, that four independently controlled muscle units (three of which survived at 5 months) could be created from residual brachial nerves anastomosed to nerve segments originally supplying the pectoralis major and smaller muscles [69]. Termed targeted muscle reinnervation (TMR) (Fig. 5), this landmark procedure allowed the patient to perform simultaneous control of two degrees of freedom at the elbow and wrist of a prosthetic arm, using standard reconstructive techniques and without the need for implantable devices [70]. TMR has since developed, 


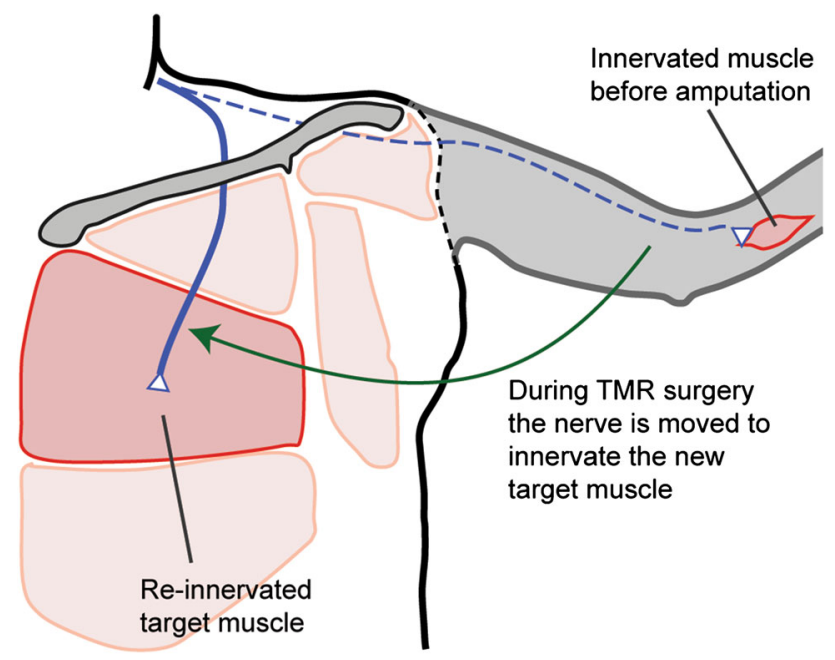

Fig. 5 A simple schematic of the TMR procedure. Surviving nerves are co-apted to nerves supplying surviving muscle groups. In the case of this image, the pectoralis muscles are used to amplify the EMG signals generated by radial nerve activity

incorporating more patients [71, 72], and also describing the transfer of hand sensation to the area where nerves have been re-directed [73]. Notably, this technique has not only allowed multifunctional control of prosthetic limbs in realtime [74] but has also acted as a catalyst for further development into EMG processing for prosthetic control.

Clinically, prosthetic limbs only use a few electrodes (between 2 and 6) to describe the most important movements, even in patients who have undergone TMR surgery. However, recent attempts to harness the full spectrum of EMG signals available have shown that high density (HD) EMG can provide the full discharge patterns of active motor units [74-77], which may be a future alternative source of control.

\section{Future Directions}

\section{Closing the Loop}

One particular area that needs to be addressed clinically to improve prosthetic control is to complete the control loop itself. Delicately holding a fragile object requires an intact sensory-motor integration system that finely balances executed motor commands in response to appropriate sensory stimuli. Current prosthetic technology does not possess sufficient tactile feedback, if any at all, to replace that of human touch, so current control strategies rely primarily on visual feedback [78].

To address the reliance on visual feedback, new research is attempting to improve the use of tactile feedback. TMR has demonstrated that not only were motor nerves transferred to new muscles but also some sensory nerves. In a shoulder disarticulation patient's reinnervated regions, tactile stimuli gave the sensation of being touched on the missing limb, while still being able to differentiate hand from chest sensation [73]. In addition, using a haptic device, which transmitted vibration from the prosthetic limb to the amputee's reinnervated skin, encouraged the patient to include the prosthesis as part of his self-image, as opposed to a foreign entity [79]. Separately, in a transradial amputee, in whom intraneural implant electrodes were stimulated to provide sensory feedback via the median and ulnar nerves to complete a motor control task, it was shown that success rates increased significantly compared to just visual feedback [80].

\section{Virtual Rehabilitation Environments}

Another concept that works around the limitations of only having visual feedback is the use of a virtual rehabilitation environment (VRE) to improve prosthetic control (Fig. 6). In the context of this review, a VRE refers to a computerbased system, presenting to the subject a visualization of a task to be completed. The subject is able to control elements of the VRE using muscle activation, perceiving visual feedback by graphical representation. The VRE is capable of both assessing the performance of the control algorithms as well as training prosthetic users before actual use of the device.

In terms of evaluating control algorithm performance, a VRE can be used in online scenarios. First demonstrated in 2003, VREs allowed the user to control virtual hand movements using EMG patterns [81]. More advanced VREs have since been developed, providing more realistic graphics and increased function $[82,83]$, as well as interactions with virtual objects [84]. Formal performance assessment of control algorithms was validated using the target achievement control tests [38•], in which prosthetic users steered a virtual prosthesis into a predefined target position. This concept was streamlined using an abstract but more intuitive VRE paradigm of a simple arrow reaching circular targets [55].

VREs are also beneficial in training prosthetic users. After an amputation, the patient usually undergoes a long rehabilitation process (up to 6 months), including the healing phase of the affected upper extremity, before they can be fitted with their prosthesis. Currently available training systems are simple, such as the Otto Bock MyoBoy (http://www.ottobock.de/cps/rde/xchg/ob_com_en/hs. $\mathrm{xsl} / 3795$.html), and can be used to train the muscles necessary for direct control of commercially available hand prostheses. However, it would be beneficial to train users in more challenging scenarios, such as grasping virtual objects, which would facilitate the learning process. Consequently, VRE systems can provide an environment 
(a)

Haptic Feedback
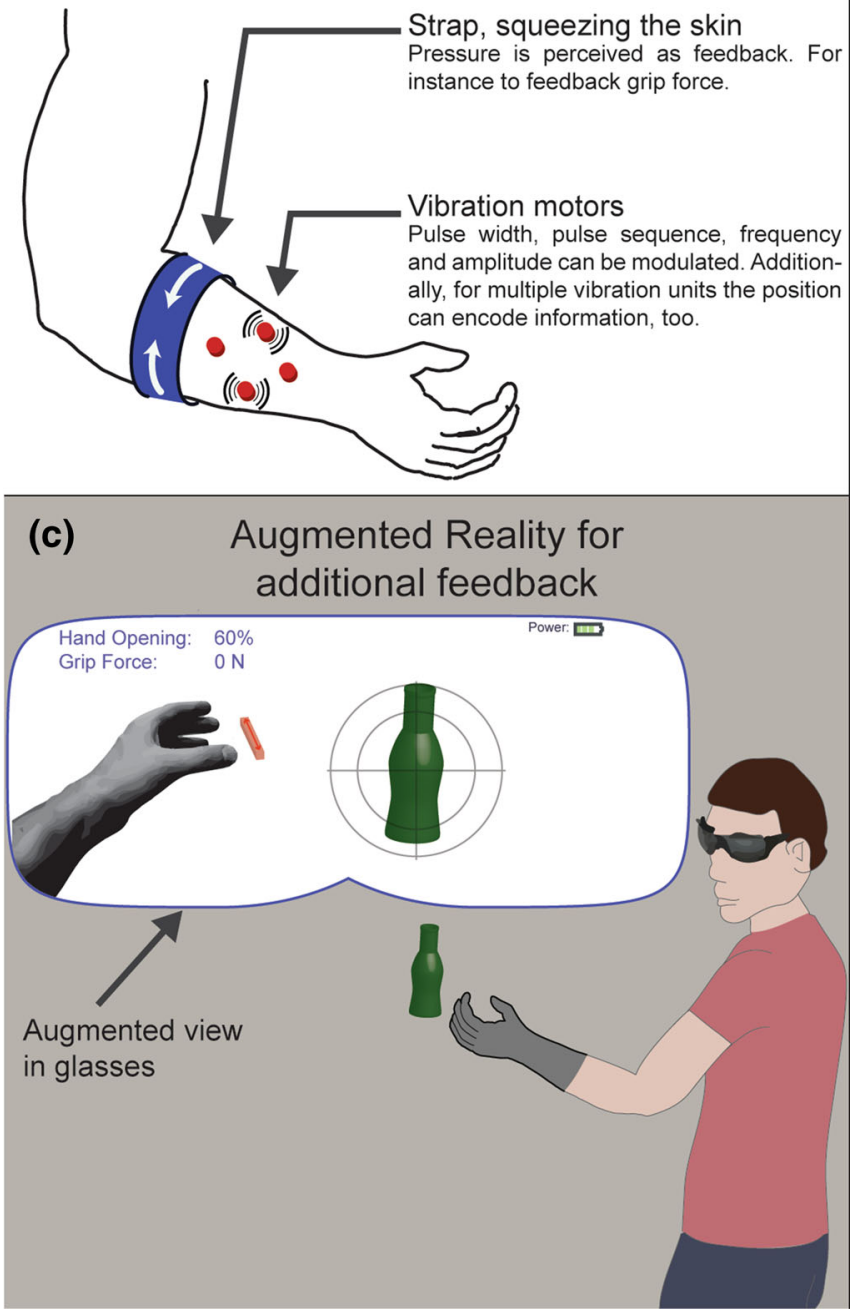

Fig. 6 Future perspectives in enhancing prosthesis control and training. By providing feedback, the user can get additional information for instance about the grip force. Possible modalities are haptic feedback (a), electrocutaneous stimulation (b) or an augmented

shortly after amputation to perfect prosthesis control even before fitting [38•, 74, 85, 86]. Despite these advantages, this application of VRE in myoelectric control is still not widely established.

\section{Implantable Methods}

Whilst surface EMG control methods are currently the most applicable, there has also been significant progress in implanted recording methods. Peripheral nerve function has been shown to remain intact many years after amputation [87], and successful direct nerve recording systems have been demonstrated in amputees [80, 88, 89], as well as cortical recording in patients with spinal cord injuries

(b) Electrocutaneous Stimulation Feedback

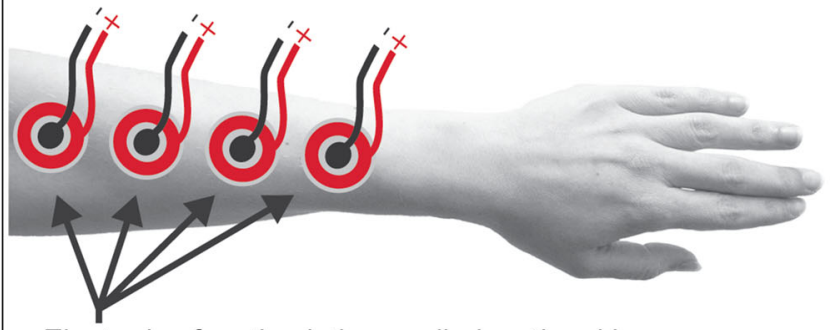

Electrodes for stimulation applied on the skin

Each electrode can be used independently and modulated in frequency, amplitude, pulse width and pulse sequence. Depending on the settings, the sensation can be tickling, tingling, tapping, or even pain. Additionally, the position of the electrodes can also encode information.

(d) Virtual Rehabilitation Environment including interaction with objects

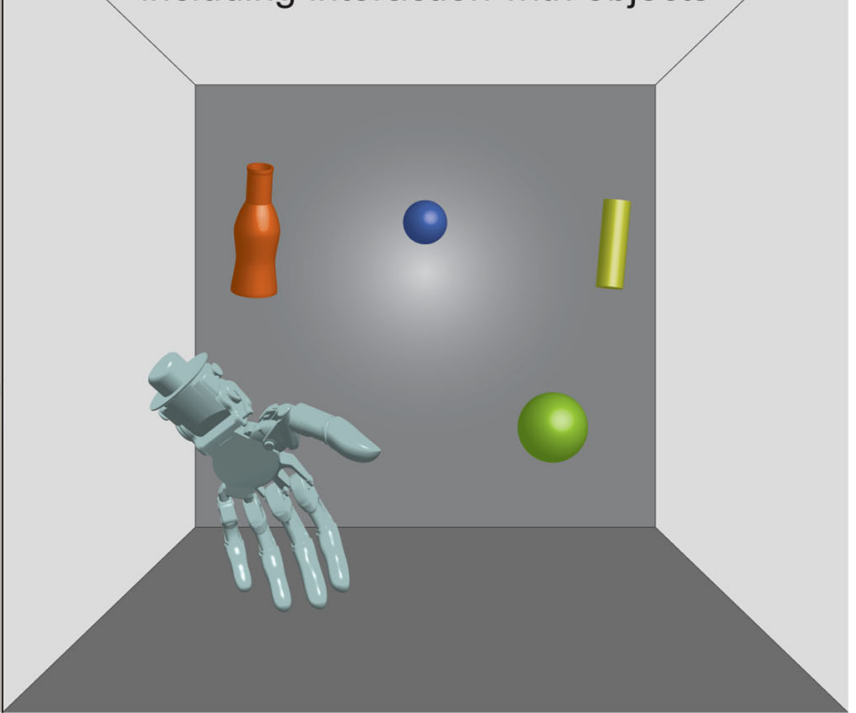

reality [92], i.e. with Google Glasses (c). Finally, virtual rehabilitation environments (d) can be used to provide early training after amputation

[90, 91]. In addition, it may be possible to permanently link implanted electrodes through a bone-anchored conduit [22] or wirelessly [20]. While these examples are either animal or single case studies and are far from general clinical use, they offer an insight into alternative avenues of how future prosthetic limbs might be controlled.

\section{Conclusions}

Considerable work has been done in feed-forward control to improve the manner in which amputees interact with their prostheses. However, there are still challenges that are not easily overcome for clinical use. Key areas to address 
are the speed and reliability of control in achieving multifunctional movement. Newer regression control algorithms may combine the best features of the preceding algorithms but are only in the infancy of their development. In addition, improving the sensory input beyond just visual feedback will be key to more fluent control. In the meantime, innovative systems such as VREs enable current amputees to engage with their prosthesis and hopefully reduce the rejection rate.

\section{Compliance with Ethics Guidelines}

Conflict of Interest This review is based on the authors' work through financing by the Austrian Ministry of Commerce via the Christian Doppler Research Foundation, the German Ministry for Education and Research (BMBF) via the Bernstein Focus Neurotechnology (BFNT) Göttingen under Grant No. 01GQ0810; European Commission via the Industrial Academia Partnerships and Pathways (IAPP) under Grants No. 251555 (AMYO) and No. 286208 (MYOSENS); and the European Research Council (ERC) via the ERC Advanced Grant DEMOVE (No. 267888). Aidan D. Roche, Hubertus Rehbaum, Dario Farina, and Oskar C. Aszmann declare that they have no conflict of interest.

Human and Animal Rights and Informed Consent This article does not contain any studies with animal subjects performed by any of the authors. With regard to the authors' research cited in this paper, all procedures were followed in accordance with the ethical standards of the responsible committee on human experimentation and with the Helsinki Declaration of 1975, as revised in 2000 and 2008.

\section{References}

References of interest which have been published recently are noted as:

- Of importance

1. Childress DS. Historical aspects of powered limb prostheses. Clin Prosthet Orthot. 1985;9(1):2-13. http://www.oandplibrary.org/ cpo/1985_01_002.asp.

2. - Peerdeman B, Boere D, Witteveen H, Huis in 'tVeld R, Hermens H, Stramigioli S, et al. Myoelectric forearm prostheses: State of the art from a user-centered perspective. J Rehabil Res Dev. 2011; 48:719. Available from: http://www.rehab.research. va.gov/jour/11/486/pdf/peerdeman486.pdf. Accessed 27 Oct 2013. A comprehensive review of prosthetic requirements from the patient's perspective, in contrast to the often limited view of the researcher.

3. Scott R. Myoelectric control of prostheses: A brief history. Proc MyoElectric Control Prosthetics Symp. Fredericton, New Brunswick, Canada 1992. http://dukespace.lib.duke.edu/dspace/ handle/10161/4817 (1992).

4. Scott RN, Parker PA. Myoelectric prostheses: state of the art. J Med Eng Technol. 1988;12:143-51. http://www.ncbi.nlm.nih. gov/pubmed/3057209.

5. Oskoei MA, Hu H. Myoelectric control systems-a survey. Biomed Signal Process Control. 2007;2:275-94.

6. Li G, Schultz AE, Kuiken TA. Quantifying pattern recognitionbased myoelectric control of multifunctional transradial prostheses. IEEE Trans Neural Syst Rehabil Eng. 2010;18:185-92. http://www.pubmedcentral.nih.gov/articlerender.fcgi?artid=30249 $15 \&$ tool $=$ pmcentrez\&rendertype $=$ abstract.

7. Not Available NA. In memoriam Reinhold Reiter 17(November), pp. 1920-1924, September 1998. Int J Biometeorol. 1999;43: 96-8. http://link.springer.com/10.1007/s004840050122.

8. Battye CK, Nightingale A, Whillis J. The use of myo-electric currents in the operation of prostheses. J Bone Joint Surg Br. 1955;37:506-10. http://web.jbjs.org.uk/cgi/content/abstract/37-B/3/506.

9. Kobrinskiy AE. Utilization of bio-currents for control purposes. 1959.

10. Kobrinskiy AE. Bioelectrical control of prosthetic devices. Her Acad Sci. 1960;30:58-61.

11. Popov B. The bio-electrically controlled prosthesis. J Bone Joint Surg Br. 1965;47:421-4. http://www.bjj.boneandjoint.org.uk/ content/47-B/3/421.abstract.

12. Scott RN. Myoelectric control of prostheses and orthoses. Bull Prosthet Res. 1967;7:93. http://www.rehab.research.va.gov/jour/ 67/4/1/93.pdf.

13. Asghari Oskoei M, Hu H. Myoelectric control systems-a survey. Biomed Signal Process Control. 2007;2:275-94. http:// linkinghub.elsevier.com/retrieve/pii/S1746809407000547.

14. Carozza MC, Cappiello G, Stellin G, Zaccone F, Vecchi F, Micera $\mathrm{S}$, et al. On the development of a novel adaptive prosthetic hand with compliant joints: experimental platform and EMG control. 2005 IEEE/RSJ Int Conf Intell Robot Syst. IEEE; 2005; p. 1271-6. http://ieeexplore.ieee.org/articleDetails.jsp?arnumber=1545585.

15. Bottomley A, Cowell T. An artificial hand controlled by the nerves. New Sci. 1964;21:668-71.

16. Bottomley A, Styles P, Jilbert P, Birtill J, Truscott J. Prosthetic hand with improved control system for activation by electromyogram signals. US Patent $3,418,662 ; 1968$. Available from: http://patft.uspto.gov/netacgi/nph-Parser?Sect1=PTO1\&Sect2= HITOFF $\& \mathrm{~d}=\mathrm{PALL} \& \mathrm{p}=1 \& \mathrm{u}=\% 2 \mathrm{Fnetahtml} \% 2 \mathrm{FPTO} \% 2 \mathrm{Fsrchnum}$. $\mathrm{htm} \& \mathrm{r}=1 \& \mathrm{f}=\mathrm{G} \& \mathrm{l}=50 \& \mathrm{~s} 1=3418662 . \mathrm{PN} . \& \mathrm{OS}=\mathrm{PN} / 3418662 \& \mathrm{RS}=$ PN/3418662. Accessed 10 July 2013.

17. • Fougner A, Stavdahl O, Kyberd PJ, Losier YG, Parker PA. Control of upper limb prostheses: terminology and proportional myoelectric control-a review. IEEE Trans Neural Syst Rehabil Eng. 2012;20: 663-77. Available from: http://www.ncbi.nlm.nih.gov/pubmed/ 22665514. Accessed 29 May 2013. A useful review paper that attempts to unify the nomenclature used in myoelectric prosthesis control.

18. Parker P, Englehart K, Hudgins B. Myoelectric signal processing for control of powered limb prostheses. J Electromyogr Kinesiol. 2006;16:541-8. http://www.ncbi.nlm.nih.gov/pubmed/17045489.

19. De Luca CJ, Merletti R. Surface myoelectric signal cross-talk among muscles of the leg. Electroencephalogr Clin Neurophysiol. 1988;69:568-75

20. Weir ff RF, Troyk PR, DeMichele GA, Kerns DA, Schorsch JF, Maas H. Implantable myoelectric sensors (IMESs) for intramuscular electromyogram recording. IEEE Trans Biomed Eng. 2009;56: 159-71. http://www.pubmedcentral.nih.gov/articlerender.fcgi?artid= 3157946\&tool $=$ pmcentrez\&rendertype $=$ abstract.

21. Baker JJ, Scheme E, Englehart K, Hutchinson DT, Greger B. Continuous detection and decoding of dexterous finger flexions with implantable myoelectric sensors. IEEE Trans Neural Syst Rehabil Eng. 2010;18:424-32. http://www.ncbi.nlm.nih.gov/pub med/20378481.

22. Al-Ajam Y, Lancashire H, Pendegrass C, Kang N, Dowling RP, Taylor SJG, et al. The use of a bone-anchored device as a hardwired conduit for transmitting EMG signals from implanted muscle electrodes. IEEE Trans Biomed Eng IEEE. 2013;60:1654-9. http://ieeexplore.ieee.org/xpls/abs_all.jsp?arnumber=6417997.

23. Graupe D, Cline WK. Functional separation of EMG signals via ARMA identification methods for prosthesis control purposes. 
IEEE Trans Syst Man Cybern. 1975;5:252-9. http://ieeexplore. ieee.org/xpls/abs_all.jsp?arnumber $=5408479$.

24. Herberts P, Almström C. Hand prosthesis control via myoelectric patterns. Acta Orthop. 1973;44:389-409. http://informahealthcare. com/doi/pdf/10.3109/17453677308989075.

25. Finley FR, Wirta RW. Myocoder studies of multiple myopotential response. Arch Phys Med Rehabil. 1967;48:598-601. http:// www.ncbi.nlm.nih.gov/pubmed/6060789.

26. Hudgins B, Parker P, Scott RN. A new strategy for multifunction myoelectric control. IEEE Trans Biomed Eng. 1993;40:82-94. http://ieeexplore.ieee.org/xpls/abs_all.jsp?arnumber=204774.

27. Scheme E, Englehart K. Electromyogram pattern recognition for control of powered upper-limb prostheses: state of the art and challenges for clinical use. J Rehabil Res Dev. 2011;48:643. http://www.rehab.research.va.gov/jour/11/486/pdf/scheme486. pdf.

28. Kuruganti U, Hudgins B, Scott RN. Two-channel enhancement of a multifunction control system. IEEE Trans Biomed Eng. 1995;42:109-11. http://www.ncbi.nlm.nih.gov/pubmed/7851924.

29. Almström C, Herberts P, Körner L. Experience with Swedish multifunctional prosthetic hands controlled by pattern recognition of multiple myoelectric signals. Int Orthop. 1981;5(1):15-21. http://link.springer.com/article/10.1007/BF00286094.

30. Doerschuk PC, Gustafson DE, Willsky AS. Upper extremity limb function discrimination using EMG signal analysis. IEEE Trans Biomed Eng. 1983;30:18-29. http://www.ncbi.nlm.nih.gov/ pubmed/6826182.

31. Saridis GN, Gootee TP. EMG pattern analysis and classification for a prosthetic arm. IEEE Trans Biomed Eng. 1982;29:403-12. http://www.ncbi.nlm.nih.gov/pubmed/7106790.

32. Englehart K, Hudgins B, Parker PA. A wavelet-based continuous classification scheme for multifunction myoelectric control. IEEE Trans Biomed Eng. 2001;48:302-11. http://www.ncbi.nlm.nih. gov/pubmed/11327498.

33. Tsenov G, Zeghbib AH, Palis F, Shoylev N, Mladenov V. Neural networks for online classification of hand and finger movements using surface EMG signals. Neural Netw Appl Electr Eng. 2006. 8th Seminar; p. 167-71. Available from: http://ieeexplore.ieee. org/lpdocs/epic03/wrapper.htm?arnumber $=4147191$. Accessed 17 July 2013.

34. Tenore F, Ramos A, Fahmy A, Acharya S, Etienne-Cummings R, Thakor NV. Towards the control of individual fingers of a prosthetic hand using surface EMG signals. Confernece Proceedings of IEEE Engineering in Medicine and Biology Society; 2007. pp. 6146-6149. Available from: http://www.ncbi.nlm.nih. gov/pubmed/18003418. Accessed 17 July 2013.

35. Smith RJ, Huberdeau D, Tenore F, Thakor NV. Real-time myoelectric decoding of individual finger movements for a virtual target task. Confernece Proceedings of IEEE Engineering in Medicine and Biology Society; 2009. pp. 2376-2379. Available from: http://www.ncbi.nlm.nih.gov/pubmed/19965192. Accessed 17 July 2013

36. Khushaba RN, Kodagoda S, Takruri M, Dissanayake G. Toward improved control of prosthetic fingers using surface electromyogram (EMG) signals. Expert Syst Appl. 2012;39: 10731-10738. Available from: http://linkinghub.elsevier.com/ retrieve/pii/S0957417412004654. Accessed 17 July 2013.

37. Dosen S, Muller K-R, Farina D. Myoelectric control of artificial limbs-is there a need to change focus? [In the spotlight]. IEEE Signal Process Mag. 2012;29:150-2. http://ieeexplore.ieee.org/ lpdocs/epic03/wrapper.htm?arnumber=6279589.

38. - Simon AM, Hargrove LJ, Lock BA, Kuiken TA. Target achievement control test: evaluating real-time myoelectric pattern-recognition control of multifunctional upper-limb prostheses. J Rehabil Res Dev. 2011;48:619. Available from: http://www. rehab.research.va.gov/jour/11/486/pdf/simon486.pdf. Accessed
16 Oct 2013. One of the first publications focussing on online assessment of myoeletric control systems, moving away from the offline analysis as a non-realistic evaluation.

39. Young AJ, Hargrove LJ. Effects of interelectrode distance on the robustness of myoelectric pattern recognition systems 2011 nnual International Conference of the IEEE Engineering in Medicine and Biology Society; 2011. pp. 3873-38789. Available from: http://www.ncbi.nlm.nih.gov/pubmed/22255185. Accessed 13 Oct 2013.

40. Young AJ, Hargrove LJ, Kuiken TA. Improving myoelectric pattern recognition robustness to electrode shift by changing interelectrode distance and electrode configuration. IEEE Trans Biomed Eng. 2012;59:645-652. http://www.ncbi.nlm.nih.gov/ pubmed/22147289.

41. Jiang N, Vujaklija I, Rehbaum H, Graimann B, Farina D. Is accurate mapping of emg signals on kinematics needed for precise online myoelectric control? IEEE Trans Neural Syst Rehabil Eng. 2013.

42. Farrell TR, Weir RF. The optimal controller delay for myoelectric prostheses. Neural Syst Rehabil Eng. 2007;15:111-118.

43. Paciga JE, Richard PD, Scott RN. Error rate in five-state myoelectric control systems. Med Biol Eng Comput. 1980;18:287-290. http://link.springer.com/10.1007/BF02443381.

44. Englehart K, Hudgins B. A robust, real-time control scheme for multifunction myoelectric control. Biomed Eng IEEE Trans. 2003;50:848-854.

45. Huang Y, Englehart KB, Hudgins B, Chan ADC. A Gaussian mixture model based classification scheme for myoelectric control of powered upper limb prostheses. IEEE Trans Biomed Eng. 2005;52:1801-1811. http://www.ncbi.nlm.nih.gov/pubmed/16285383.

46. Chan ADC, Englehart KB. Continuous myoelectric control for powered prostheses using hidden Markov models. IEEE Trans Biomed Eng. 2005;52:121-124. http://www.ncbi.nlm.nih.gov/ pubmed/15651571.

47. Chu J-U, Moon I, Mun M-S. A real-time EMG pattern recognition system based on linear-nonlinear feature projection for a multifunction myoelectric hand. IEEE Trans Biomed Eng. 2006;53: 2232-9. http://www.ncbi.nlm.nih.gov/pubmed/17073328.

48. Ajiboye $A B$, Weir ff RF. A heuristic fuzzy logic approach to EMG pattern recognition for multifunctional prosthesis control. IEEE Trans Neural Syst Rehabil Eng. 2005;13:280-91. http:// www.ncbi.nlm.nih.gov/pubmed/16200752.

49. Biddiss E, Beaton D, Chau T. Consumer design priorities for upper limb prosthetics. Disabil Rehabil Assist Technol. 2007;2: 346-57. http://informahealthcare.com/doi/abs/10.1080/174831007 01714733.

50. Østlie K, Lesjø IM, Franklin RJ, Garfelt B, Skjeldal OH, Magnus P. Prosthesis rejection in acquired major upper-limb amputees: a population-based survey. Disabil Rehabil Assist Technol. 2012; 7:294-303. http://www.ncbi.nlm.nih.gov/pubmed/22112174.

51. Englehart K, Hudgins B. A robust, real-time control scheme for multifunction myoelectric control. Biomed Eng IEEE Trans. 2003;50:848-54

52. Young A, Smith L, Rouse E, Hargrove L. Classification of simultaneous movements using surface EMG pattern recognition. IEEE Trans Biomed Eng. 2012.

53. Simon AM, Stern K, Hargrove LJ. A comparison of proportional control methods for pattern recognition control. Confernece Proceedings of IEEE Engineering in Medicine and Biology Society; 2011. p. 3354-7.

54. Jiang N, Englehart KB, Parker PA. Extracting simultaneous and proportional neural control information for multiple-DOF prostheses from the surface electromyographic signal. IEEE Trans Biomed Eng. 2009;56:1070-80.

55. Rehbaum H, Jiang N, Paredes L, Amsuess S, Graimann B, Farina D. Real time simultaneous and proportional control of multiple 
degrees of freedom from surface EMG: preliminary results on subjects with limb deficiency. Annu Int Conf IEEE Eng Med Biol Soc IEEE; 2012. p. 1346-9.

56. - Jiang N, Rehbaum H, Vujaklija I, Graimann B, Farina D. Intuitive, Online, simultaneous and proportional myoelectric control over two degrees of freedom in upper limb amputees. IEEE Trans Neural Syst Rehabil Eng. 2013; Available from: http://www.ncbi.nlm.nih.gov/pubmed/23996582. Accessed 16 Oct 2013. Highlighting regression methods as a new control strategy for myoelecric prostheses.

57. Nielsen JLG, Holmgaard S, Jiang N, Englehart K, Farina D, Parker P. Enhanced EMG signal processing for simultaneous and proportional myoelectric control. Conference Proceedings of IEEE Engineering in Medicine and Biology Society; 2009. p. 4335-4338.

58. Muceli S, Jiang N, Farina D. Multichannel surface EMG based estimation of bilateral hand kinematics during movements at multiple degrees of freedom. Conference Proceedings of IEEE Engineering in Medicine and Biology Society. 2010; p. 6066-6069.

59. Nielsen JLG, Holmgaard S, Jiang N, Englehart KB, Farina D, Parker PA. Simultaneous and proportional force estimation for multifunction myoelectric prostheses using mirrored bilateral training. IEEE Trans Biomed Eng. 2011;58:681-8.

60. Jiang N, Muceli S, Graimann B, Farina D. Effect of arm position on the prediction of kinematics from EMG in amputees. Med Biol Eng Comput. 2012.

61. Muceli S, Farina D. Simultaneous and proportional estimation of hand kinematics from EMG during mirrored movements at multiple degrees-of-freedom. IEEE Trans Neural Syst Rehabil Eng. 2012;20:371-8.

62. Kamavuako EN, Englehart KB, Jensen W, Farina D. Simultaneous and proportional force estimation in multiple degrees of freedom from intramuscular EMG. IEEE Trans Biomed Eng. 2012;59:1804-7.

63. Hahne JM, Rehbaum H, Biessmann F, Meinecke FC, Muller K-R, Jiang N, et al. Simultaneous and proportional control of 2D wrist movements with myoelectric signals. 2012 IEEE Int Work Mach Learn Signal Process. 2012; p. 1-6.

64. Muceli S, Jiang N, Farina D. Extracting signals robust to electrode number and shift for online simultaneous and proportional myoelectric control by factorization algorithms. IEEE Trans Neural Syst Rehabil Eng. 2013.

65. Kuiken TA, Childress DS, Rymer WZ. The hyper-reinnervation of rat skeletal muscle. Brain Res. 1995;676:113-23 . http://www. ncbi.nlm.nih.gov/pubmed/7796162.

66. Kuiken TA. Consideration of nerve-muscle grafts to improve the control of artificial arms. Technol Disabil. 2003;15:105-11. http:// www.smpp.nwu.edu/savedLiterature/Kuiken(2004)J.TechnolDisabil 15(2)105-111.doc

67. Lowery MM, Stoykov NS, Kuiken TA. Independence of myoelectric control signals examined using a surface EMG model. IEEE Trans Biomed Eng. 2003;50:789-93. http://www.ncbi.nlm. nih.gov/pubmed/12814247.

68. Kuiken T, Lowery M, Stoykov N. The effect of subcutaneous fat on myoelectric signal amplitude and cross-talk. Prosthet Orthot. 2003;27(1):48-54. http://www.oandplibrary.org/poi/pdf/1997_01.pdf.

69. Kuiken TA, Dumanian GA, Lipschutz RD, Miller LA, Stubblefield KA. The use of targeted muscle reinnervation for improved myoelectric prosthesis control in a bilateral shoulder disarticulation amputee. Prosthet Orthot Int. 2004;28:245-53. http://www. ncbi.nlm.nih.gov/pubmed/15658637.

70. Hijjawi JB, Kuiken TA, Lipschutz RD, Miller LA, Stubblefield KA, Dumanian GA. Improved myoelectric prosthesis control accomplished using multiple nerve transfers. Plast Reconstr Surg. 2006;118:1573-8. http://www.ncbi.nlm.nih.gov/pubmed/17102 730.
71. Kuiken TA, Miller LA, Lipschutz RD, Lock BA, Stubblefield K, Marasco PD, et al. Targeted reinnervation for enhanced prosthetic arm function in a woman with a proximal amputation: a case study. Lancet. 2007;369:371-80. http://dx.doi.org/10.1016/ S0140-6736(07)60193-7.

72. O'Shaughnessy KD, Dumanian GA, Lipschutz RD, Miller LA, Stubblefield K, Kuiken TA. Targeted reinnervation to improve prosthesis control in transhumeral amputees. A report of three cases. J Bone Joint Surg Am. 2008;90:393-400. http://www.ncbi. nlm.nih.gov/pubmed/18245601.

73. Kuiken TA, Marasco PD, Lock BA, Harden RN, Dewald JPA. Redirection of cutaneous sensation from the hand to the chest skin of human amputees with targeted reinnervation. Proc Natl Acad Sci USA. 2007;104:20061-6. http://www.pubmedcentral. nih.gov/articlerender.fcgi?artid=2148422\&tool=pmcentrez\&render type $=$ abstract.

74. Kuiken TA, Li G, Lock BA, Lipschutz RD, Miller LA, Stubblefield $\mathrm{KA}$, et al. Targeted muscle reinnervation for real-time myoelectric control of multifunction artificial arms. JAMA. 2009;301:619-28. http://jama.ama-assn.org/cgi/content/abstract/301/6/619.

75. Holobar A, Minetto MA, Botter A, Negro F, Farina D. Experimental analysis of accuracy in the identification of motor unit spike trains from high-density surface EMG. IEEE Trans Neural Syst Rehabil Eng. 2010;18:221-9. http://www.ncbi.nlm.nih.gov/ pubmed/20144921.

76. Holobar A, Farina D, Gazzoni M, Merletti R, Zazula D. Estimating motor unit discharge patterns from high-density surface electromyogram. Clin Neurophysiol. 2009;120:551-62. http:// www.sciencedirect.com/science/article/pii/S1388245709000030.

77. Holobar A, Zazula D. Multichannel blind source separation using convolution kernel compensation. IEEE Trans Signal Process. 2007;55:4487-96.

78. Zecca M, Micera S, Carrozza MC, Dario P. Control of multifunctional prosthetic hands by processing the electromyographic signal. Crit Rev Biomed Eng. 2002;30:459-85. http://www.ncbi. nlm.nih.gov/pubmed/12739757.

79. Marasco PD, Kim K, Colgate JE, Peshkin MA, Kuiken TA. Robotic touch shifts perception of embodiment to a prosthesis in targeted reinnervation amputees. Brain. 2011;134:747-58. http:// www.pubmedcentral.nih.gov/articlerender.fcgi?artid=3044830\&tool= pmcentrez\&rendertype $=$ abstract.

80. Rossini PM, Micera S, Benvenuto A, Carpaneto J, Cavallo G, Citi L, et al. Double nerve intraneural interface implant on a human amputee for robotic hand control. Clin Neurophysiol. 2010;121:777-83; http:// www.ncbi.nlm.nih.gov/pubmed/20110193.

81. Soares A, Andrade A. The development of a virtual myoelectric prosthesis controlled by an EMG pattern recognition system based on neural networks. J Intell Inf Syst. 2003;21(2):127-41.

82. Hauschild M, Davoodi R, Loeb GE. A virtual reality environment for designing and fitting neural prosthetic limbs. IEEE Trans Neural Syst Rehabil Eng. 2007;15:9-15.

83. Lock B, Englehart K, Hudgins B. Real-time myoelectric control in a virtual environment to relate usability vs. accuracy. MyoElectric Control Symp. 2005;17-20.

84. Hargrove L, Losier Y, Lock B, Englehart K, Hudgins B. A realtime pattern recognition based myoelectric control usability study implemented in a virtual environment. Conference Proceedings of IEEE Engineering in Medicine and Biology Society; 2007. p. $4842-5$.

85. Takeuchi T, Wada T, Mukobaru M, Doi S. A Training system for myoelectric prosthetic hand in virtual environment. 2007 IEEE/ ICME Int Conf Complex Med Eng. IEEE; 2007. p. 1351-1356.

86. Resnik L, Etter K, Klinger SL, Kambe C. Using virtual reality environment to facilitate training with advanced upper-limb prosthesis. J Rehabil Res Dev. 2011;48:707. http://www.rehab. research.va.gov/jour/11/486/pdf/resnik2486.pdf. 
87. Dhillon GS, Lawrence SM, Hutchinson DT, Horch KW. Residual function in peripheral nerve stumps of amputees: implications for neural control of artificial limbs. J Hand Surg Am. 2004;29: 605-15 discussion 616-618. http://www.ncbi.nlm.nih.gov/pub med/15249083.

88. Dhillon GS, Horch KW. Direct neural sensory feedback and control of a prosthetic arm. IEEE Trans Neural Syst Rehabil Eng. 2005;13:468-72. http://www.ncbi.nlm.nih.gov/pubmed/16425828.

89. Jia X, Koenig MA, Zhang X, Zhang J, Chen T, Chen Z. Residual motor signal in long-term human severed peripheral nerves and feasibility of neural signal-controlled artificial limb. J Hand Surg Am. 2007;32:657-66. http://www.ncbi.nlm.nih.gov/pubmed/1748 2005.
90. Hochberg LR, Serruya MD, Friehs GM, Mukand JA, Saleh M, Caplan AH, et al. Neuronal ensemble control of prosthetic devices by a human with tetraplegia. Nature. 2006;442:164-71. http://www.ncbi.nlm.nih.gov/pubmed/16838014.

91. Collinger JL, Wodlinger B, Downey JE, Wang W, Tyler-Kabara EC, Weber DJ, et al. High-performance neuroprosthetic control by an individual with tetraplegia. Lancet. 2013;381:557-64. http://www.ncbi.nlm.nih.gov/pubmed/23253623.

92. Markovic M, Dosen S, Farina D, Popovic D, Graimann B. Sensor fusion for control of upper limb prostheses: integration of myoelectric control with stereovision, augmented reality and inertial sensing. European Patent; 2013. Available from: http://www.nre. bccn.uni-goettingen.de/index.php?id=216. Accessed 4 Nov 2013. 